\title{
Regulatory Role of Local Immune Response During the Early Pregnancy in Cattle
}

\author{
Ragab M Fereig* \\ Department of Animal Medicine, South Valley University, Egypt
}

Submission: September 08, 2018, Published: September 21, 2018

"Corresponding author: Ragab M Fereig, Department of Animal Medicine, Faculty of Veterinary Medicine, South Valley University, Qena City, Qena 83523, Egypt; Tel: 0108058497; 0965218559, Email: ragabmakhlouf84@yahoo.com

\begin{abstract}
The phenomenon of warm welcome of the uterus to conceptus but not allograft implantation is still ambiguous. In cattle, pregnancy is a highly important physiological process that has a significant economical consideration due to relevance to meat and milk production. Immune system is highly incorporated in development of fetus and fetal membranes. Interferon tau (IFNT) is a type I interferon is reported as crucial molecule for adequate conceptus implantation. Early programmed immune response via numerous pathways is essential for completion of pregnancy. Toll-like receptors (TLRs) are the pivotal innate immune receptors that recognize pathogen specific molecular patterns (PAMPs) in an adequate, potent pathway and enhance specific immune signaling that culminates in triggering antigen-specific adaptive responses. Numerous reports revealed the expression of different TLRs in both male and female germ cells. In this review, we attempt to discuss briefly the role of essential signaling pathways in the stages of conception, implantation, and early pregnancy peculiarly TLR2 and IFNT. The recognition of key molecules in such anaforementioned stage would contribute in increasing the conception rate, and subsequently enhancing the animal reproduction and production.

Keywords: Implantation; Pregnancy; TLR; Interferon tau; Ruminants

Abbreviations: CD4: Cluster of Differentiation 4 is a Glycoprotein Marker for T Helper Cells; CD8:Marker for T Cytotoxic Cells; COCs: Cumulusoocyte Complex Cells; CRAMP: Cathelin-Related Antimicrobial Peptide; CXCL10: Chemokine (C-X-C motif) Ligand; EPI: Early Programmed Immunity; HA: Hyaluronan; HLA-G: Histocompatibility Antigen G or Human Leucocytic antigen G; IDO: Indolamine 2,3-Dioxygenase; IFNT: Interferon Tau (type I interferon); IL-6: Interleukin-6; JAK/STAT: Janus Kinase/Signal Transducers and Activators of Transcription Pathway; LPS: Lipopolysaccharide; MHC: Major Histocompatibility Complex; MyD88: Myeloid Differentiation Primary Response 88 Protein Molecule; NFAT: Nuclear Factor of Activated T-Cells; NF-kB: Nuclear Factor Kappa-Light-Chain-Enhancer of Activated B Cells; PAMPs: Pathogen-Associated Molecular Patterns; PGF-2: Prostaglandin F2; TLR: Toll-Like Receptor; TNF- $\alpha$ : Tumor Necrosis Factor Alpha
\end{abstract}

\section{Introduction}

\section{Early implantation and local immune regulation}

Despite proper implantation is indispensable for success of pregnancy, reports focusing on developmental and functional immunology of this period are scarce. During implantation, the uterine endometrial layer is accommodated structurally, physiologically and immunologically to receive the elongated conceptus. Interferon tau (IFNT) is a signaling molecule that secreted from trophoblastocytes into the uterine lumen during period between days $8^{\text {th }}$ to $21^{\text {st }}$. IFNT is crucial for proper implantation by promoting glandular and vascular development in maternal side and by antagonizing the luteolytic factors as PGF-2 through depletion of oxytocin receptors in the uterus [1,2]. Furthermore, IFNT was demonstrated to stimulate the maternal secretion of CXCL10 which is essential for trophoblast migration and attachment. Aside from the previous function, CXCL10 plays a significant role in immune cells migration and recruitment such as CD4, CD8 and natural killer cells that may play a protective and maintaining role during con ceptus implantation. In the same context, the maternal immune compartments play essential role in orchestrating the interactions between maternal and fetal sides [3].

Early programming of the immune system (EPI) is highly integrated in maintaining of pregnancy through normal development of the fetus and fetal membranes. Non-classical MHC class I or HLA-G is a key factor of early programmed immune response which expressed from the placenta and participates in immune tolerance during pregnancy. Proper feedback for complement system is also important to protect placenta and fetus from maternal-mediated attack and damages [4]. Additionally, normal existence and function of certain immune cells, such as T helper, regulatory T-cells, natural killer cells and natural killer T cells is essential to prevent fetal and placental deformities [5,6]. Moreover, EPI is strongly regulated via indolamine 2,3-dioxygenase (IDO) through the degradation of tryptophan amino acid and the resultant kynurenines by hindering the T cell activation [7]. 


\section{Toll-like receptor 2-dependent signaling pathway and} reproduction

Numerous reports revealed the expression of different TLRs in both male and female germ cells. In females, the cumulus cells are surrounding the fully mature oocyte and responsible for its nourishment and protection forming cumulus-oocyte complex (COCs) $[8,9]$. In a response to bacterial infections, ovulated COCs release some immune effector molecules such as transferrin, CRAMP, IL6, TNF- $\alpha$, and PGE2 which play an essential role in counteract of microbial infections. This triggering mechanism was dependent on TLR2 and TLR4-MyD88 complex and orchestrated via NF-kB signaling pathway. Another pathway, that might be critical for successful accomplishment of ovulation, is hyaluronan (HA)-induced cytokine release. During fertilization, COCs secret HA which under the influence of sperm secreted hyaluronidase is broken down into smaller fragments. These simpler molecules were identified to enhance the production of cytokines and chemokines in a similar pathway as triggered via bacterial molecules [9].

In case of the male reproductive system, TLR2, 4 and 9 were abundantly expressed via spermatozoa particularly after exposure to bacterial or viral infection. LPS is adversely affecting the sperm function through a mechanistic pathway dependent on TLRs and mediated by caspase-signaling pathway. Sperm apoptosis and motility suppress were resultant to the induction of sperm-TLRs activation system. This finding might give an explanation to the question "the cellular mechanism of the low quality of semen induced with microbial contamination". Accordingly, the treatment of semen with endotoxin-neutralizing agents as polymixin B might improve the seminal quality by preventing the LPS-activated TLRs and subsequently accelerate the fertilization and conception rate [10].

\section{Challenges and future prospects}

Although substantial advances in the research field of fetus-mother immune interactions, the signaling pathways and triggering immune receptors are not fully revealed yet. Additionally, the interrelationship between the pregnancy-orchestrating hormones such as progesterone and the local immune system needs more studies to elucidate its molecular and cellular mechanism. Eventually, the comparative investigation of local and generalized immune responses during normal pregnancy and early fetal resorption is required for comprehensive understanding the role of local immunity in accepting or rejecting conceptus implantation.

Recently, some reports indicated the variable degree of TLRs expression during different stages of pregnancy from the trophoblast and decidual cells, but their specific roles in maintaining of pregnancy are not clear. TLRs play a crucial role in female germ cells via protecting them and improving the fertilization process through enhancement of the sperm capacitation, whilst adverse effects were noticed in sperm function by induced apoptosis and reduced sperm motility. This discrepancy is not interfering with the in vivo fertilization in the oviduct which might be attributed to the contribution of other factors and mediators in this vital process. Although the NF-kB and caspase dependent cascades were found to regulate innate immune responses in female and male germinal cells respectively, the other signaling pathways, particularly NFAT and JAK/STAT that previously demonstrated as essential cascades for fertilization and embryonic survivals should be investigated. In additions, adaptive immune response triggered via male and female germ cells should be investigated as CD4 and CD8 are abundantly recruited during the early stage of pregnancy and play pivotal role in promoting innate immune responses. Moreover, the role of germinal cells-released chemokines and cytokines might not be restricted to combating the pathogens and improving fertilization but might be contributed in cell division and further stages of embryogenesis and development.

\section{Conclusion}

Normally activated immune response is required for development of fetus and fetal membranes, not only via protection against pathogens but also for normal embryogenesis and placental evolution. The adequate fetal embedding to the endometrium is a critical phase for completion of pregnancy. IFNT is reported as a crucial molecule for adequate conceptus implantation. Additionally, both male and female germinal cells express TLRs that greatly induced in response to microbial infections. The NF-kB is the major signaling pathway regulating the immune response in COCs whilst caspase-dependent pathway is the main controller for sperm-induced immune response. Elucidating the signaling pathways of early pregnancy particularly those dependent on IFNT and TLR will have a great impact on improving the approaches of animal production and reproduction, thus increasing individual and national income.

\section{References}

1. Spencer TE, Bazer FW (2004) Conceptus signals for establishment and maintenance of pregnancy. Reprod Biol Endocrinol 2: 49.

2. Bazer FW (2013) Pregnancy recognition signaling mechanisms in ruminants and pigs. J Anim Sci Biotechnol 4(1): 23.

3. Du MR, Wang SC, Li DJ (2014) The integrative roles of chemokines at the maternal-fetal interface in early pregnancy. Cell Mol Immunol 11(5): 438-448.

4. Kuroki K, Maenaka K (2007) Immune modulation of HLA-G dimer in maternal-fetal interface. Eur J Immunol 37(7): 1727-1729.

5. Zhang J, Croy BA, Tian Z (2005) Uterine natural killer cells: Their choices, their missions. Cell Mol Immunol 2(2): 123-129.

6. Sharma S (2014) Natural killer cells and regulatory T cells in early pregnancy loss. Int J Dev Biol 58(2-4): 219-229.

7. Soliman H, Varela MM, Antonia S (2010) Indoleamine 2,3-Dioxygenase: Is It an Immune Suppressor? Cancer J 16(4): 354-359.

8. Liu Z, Shimada M, Richards JS (2008) The involvement of the Toll-like receptor family in ovulation. J Assist Reprod Genet 25(6): 223-228.

9. Shimada M (2009) Cumulus oocyte complex: Cumulus cells regulate oocyte growth and maturation. Journal of Mammalian Ova Research 26(4): 189-194.

10. Shimada M, Yanai Y, Okazaki T, Noma N, Kawashima I, et al. (2008) Hyaluronan fragments generated by sperm-secreted hyaluronidase stimulate cytokine/chemokine production via the TLR2 and TLR4 pathway in cumulus cells of ovulated COCs, which may enhance fertilization. Development 135(11): 2001-2011. 

CC $\quad$ This work is licensed under Creative

DOI: 10.19080/ARTOAJ.2018.18.556043

\section{Your next submission with Juniper Publishers will reach you the below assets}

- Quality Editorial service

- Swift Peer Review

- Reprints availability

- E-prints Service

- Manuscript Podcast for convenient understanding

- Global attainment for your research

- Manuscript accessibility in different formats

( Pdf, E-pub, Full Text, Audio)

- Unceasing customer service

Track the below URL for one-step submission https://juniperpublishers.com/online-submission.php 